\title{
Evaluation of the Minnesota Easy Culture System II Bi-Plate and Tri-Plate for identification of common mastitis pathogens in milk
}

\author{
E. Royster, ${ }^{* 1}$ S. Godden, ${ }^{*}$ D. Goulart, † A. Dahlke, ${ }^{*}$ P. Rapnicki, ${ }^{*}$ and J. Timmerman* \\ *Department of Veterinary Population Medicine, College of Veterinary Medicine, University of Minnesota, Saint Paul 55108 \\ †Department of Food Science, University of Wisconsin, Madison 53706
}

\begin{abstract}
The objective of this study was to validate use of the Minnesota Easy Culture System II Bi-Plate and Tri-Plate (University of Minnesota Laboratory for Udder Health, St. Paul) to identify common mastitis pathogens in milk. A total of 283 quarter and composite milk samples submitted to the University of Minnesota Laboratory for Udder Health during the spring of 2010 were cultured simultaneously using 3 methods: standard laboratory culture (reference method) and the Minnesota Easy Culture System II Bi-Plate and TriPlate methods. Bi-Plate and Tri-Plate cultures were incubated for 18 to $24 \mathrm{~h}$ and interpreted by 2 independent, untrained readers within $5 \mathrm{~h}$ of each other. An experienced technician completed the standard laboratory culture. For each sample, all 3 study personnel recorded the culture result (yes/no) for each of the following diagnostic categories: no bacterial growth $(\mathrm{NG})$, mixed (2 organisms), contaminated (3 or more organisms), gram-positive (GP), gram-negative (GN), Staphylococcus spp., Streptococcus spp., Streptococcus agalactiae, Streptococcus dysgalactiae, Streptococcus uberis, Enterococcus spp., Staphylococcus aureus, coagulase-negative staphylococci, Escherichia coli, Klebsiella spp., and other. For each category, the prevalence, sensitivity, specificity, accuracy, and predictive values of a positive and negative test were calculated, and the agreement between readers and between each reader and the laboratory was assessed. Specificity, overall accuracy, and negative predictive values were generally high $(>80 \%)$ for the Bi-Plate and Tri-Plate for each category. Sensitivity and positive predictive values were intermediate $(>60 \%)$ or high $(>80 \%)$ for the broad categories of NG, GP, GN, Staphylococcus spp. and Streptococcus spp., and for Staph. aureus, but were generally lower $(<60 \%)$ for other more specific categories. Similarly, interreader agreement (kappa value) was moderate to substantial (40-80\%) for the broad categories of NG, GP,
\end{abstract}

Received November 21, 2013.

Accepted February 25, 2014.

${ }^{1}$ Corresponding author: royster@umn.edu
GN, Staphylococcus spp. and Streptococcus spp., and for Staph. aureus and E. coli, but was lower for other categories. The Tri-Plate had a higher sensitivity, accuracy, and negative predictive value for Streptococcus spp., and higher interreader agreement for some of the more specific categories. Our conclusion was that BiPlate and Tri-Plate results will be most reliable when used to classify infections in broad diagnostic categories such NG, GP, or GN. The Bi-Plate and Tri-Plate will have intermediate ability to identify infections as being caused by Staphylococcus spp., Streptococcus spp., or Staph. aureus.

Key words: clinical mastitis, selective treatment, onfarm culture, bi-plate, tri-plate

\section{INTRODUCTION}

Mastitis, as one of the most costly diseases of dairy cattle, remains an important target for improved diagnostic, treatment, and management strategies. Additionally, studies have shown that the majority of antimicrobial use on dairies is related to mastitis treatment or prevention (Pol and Ruegg, 2007). As such, new mastitis control strategies must consider prudent or judicious antimicrobial use. Ideally, this means using antimicrobials only when necessary and properly targeting therapy based on a known bacterial cause.

Many instances exist when a dairy producer might choose not to treat with antimicrobials, or might select a different treatment protocol if the causal organism is known. For example, studies have shown that 10 to $40 \%$ of clinical mastitis cases are culture negative, and in these cases, intramammary (IMM) antimicrobial therapy may not be indicated (Bartlett et al., 1992; Olde Riekerink et al., 2008). Another consideration is whether (or how) to treat coliform infections. Several studies have reported a high spontaneous cure rate for gram-negative (GN) pathogens, which can account for up to $40 \%$ of cases (Guterbock et al., 1993; Morin et al., 1998; Wilson et al., 1999). Other pathogens, such as yeast, Pseudomonas spp., Mycoplasma spp., and Prototheca spp., are not susceptible to antimicrobials and are isolated in a small percentage of mastitis cases. Based on these factors, Roberson (2003) concluded that in 50 to $80 \%$ of 
mastitis cases, IMM antimicrobial therapy might not be indicated. Other studies have compared different antimicrobial treatment strategies when the specific species or category of mastitis-causing pathogen is known. For example, Schukken et al. (2013) reported higher bacteriological cure rates for mild to moderate coliform infections when a third-generation cephalosporin was used for a 5-d duration, compared with a shorter duration of therapy (2 tubes, $12 \mathrm{~h}$ apart) with a first-generation cephalosporin. Another study found improved efficacy in treating Streptococcus uberis when using IMM ceftiofur for an extended duration ( 5 or $8 \mathrm{~d}$ ) compared with the standard 2-d duration (Oliver et al., 2004). Finally, because cure rates are generally low for IMI caused by Staphylococcus aureus, especially for more chronic cases, knowing the causal organism could prompt producers to investigate other factors, such as the chronicity of the infection, and potentially forego the use of IMM antimicrobials and consider alternate methods of managing the case (Pinzón-Sánchez et al., 2011).

Clearly, many potential benefits exist to knowing the type or specific species of organism causing an IMI, including reduced antimicrobial use and risk of residue violations, and the potential for improving case outcome. Unfortunately, laboratory culture has not been routinely used by many dairies for clinical mastitis cases because of the extended turnaround time, cost, and inconvenience of submitting samples. On-farm culture (OFC) systems have been devised primarily as a way to quickly differentiate cases of clinical mastitis that would receive different treatment or management protocols. These systems rely primarily on the use of selective culture media to differentiate between categories of mastitis pathogens or, in some cases, to identify the pathogen species. Although OFC systems are not a replacement for, nor do they provide all of the diagnostic capabilities of a commercial microbiological laboratory, they have been proven accurate and valuable when used to guide strategic treatment decisions. In one large multi-state, multi-herd study, Lago et al. (2011a,b) compared the use of a selective treatment program based on OFC results [only grampositive (GP) cases received IMM antibiotics] and a treatment program in which all cases received IMM antibiotics. No significant differences in either shortor long-term health and performance outcomes were found. However, drug use was significantly reduced, with only $44 \%$ of cows assigned to the OFC system receiving IMM therapy. Another study conducted in 48 Canadian dairy herds reported a $40 \%$ decrease in drug use by using OFC to guide strategic treatment of only GP cases and concluded that cure rates and long-term health risks were not adversely affected in accurately diagnosed cases (MacDonald et al., 2011).
The Minnesota Easy Culture System II (University of Minnesota Laboratory for Udder Health, St. Paul) consists of 2 options. The Bi-Plate system is a split-culture plate with 2 types of media: MacConkey medium (selects for GN growth) and Factor medium (proprietary; selects for GP growth and inhibits GN growth). The Tri-Plate system is a culture plate split 3 ways, with the third medium being Modified TKT (MTKT) medium (proprietary; selects for catalasenegative, GP cocci). Previous studies have reported the diagnostic test characteristics of the Minnesota Easy Culture System II when used to classify clinical and subclinical mastitis infections by category of causal organism [e.g., no growth (NG), GP, GN, Staphylococcus spp., or Streptococcus spp.] or into treatment categories (treatment vs. no treatment; Jones et al., 2006; Lago et al., 2006; McCarron et al., 2009a,b). However, the question remains whether OFC can be used to make more specific classifications, perhaps at the bacterial species level. Users of OFC systems may attempt to use other factors, such as colony morphology and color changes in the medium, to identify the bacterial species present in a sample. The first edition of the Minnesota Easy Culture System II User's Manual (University of Minnesota Laboratory for Udder Health, 2004) provided guidance and images to help users identify any growth present at the species level using colony morphology and additional testing (catalase and coagulase testing). However, the reliability of the Minnesota Easy Culture System II in the hands of on-farm users to diagnose organisms beyond broad diagnostic categories (NG, GN, GP, Streptococcus spp., Staphylococcus spp., or Staph. aureus) has not previously been evaluated. The objective of this study was to describe the diagnostic test characteristics and interreader agreement for the Minnesota Easy Culture System II Bi-Plate and TriPlate systems when used to identify the cause of mastitis using both general and more specific diagnostic categories. The general diagnostic categories evaluated were NG, mixed, contaminated, GP, GN, Staphylococcus spp., and Streptococcus spp. The more specific categories evaluated were for Streptococcus agalactiae, Streptococcus dysgalactiae, Strep. uberis, Enterococcus spp., Staph. aureus, CNS, Escherichia coli, and Klebsiella spp.

\section{MATERIALS AND METHODS}

\section{Microbial Culture of Milk Samples}

Milk samples $(\mathrm{n}=283)$ submitted to the University of Minnesota Laboratory for Udder Health during the spring of 2010 were used for this study. Although descriptive information about milk samples submitted to 
the Laboratory for Udder Health was not consistently reported at the time of submission, these milk samples were a mix of quarter and composite samples from clinically mastitic cows and cows being screened for subclinical mastitis. Over half the samples were labeled with quarter identifiers [e.g., right hind $(\mathrm{RH})]$. Thirty milk samples were selected on Tuesday or Wednesday of each week during the study and an attempt was made to select samples from a variety of farms (samples used were from 47 different farms). If the samples arrived frozen, they were thawed at room temperature. The samples were then cultured simultaneously using each of 3 methods: (1) standard laboratory culture and microbiologic identification performed by an experienced laboratory technician (reference method); (2) the Minnesota Easy Culture System II Bi-Plate, interpreted individually by 2 inexperienced readers; and (3) the Minnesota Easy Culture System II Tri-Plate, interpreted individually by 2 inexperienced readers.

Standard bacteriological cultures were performed by an experienced technician at the University of Minnesota Laboratory for Udder Health according to methods described in the Laboratory Handbook on Bovine Mastitis (NMC, 1999). Samples were mixed gently and sterile cotton swabs were used to plate approximately $0.01 \mathrm{~mL}$ of milk onto half of a culture plate containing Factor medium and half of a culture plate containing MacConkey medium. Plates were incubated inverted at $37^{\circ} \mathrm{C}$ for 18 to $24 \mathrm{~h}$. Preliminary results were read at 18 to $24 \mathrm{~h}$, and further biochemical tests performed. Catalase-negative growth on Factor plates was restreaked onto MTKT plates. Plates were reincubated and final results determined at 36 to $48 \mathrm{~h}$ of incubation. Presumptive identification of staphylococci, streptococci, coliforms, or other pathogens was made based on growth characteristics, colony morphology, pattern of hemolysis, catalase testing, and Gram staining. $\beta$-Hemolytic staphylococci were tested using the tube coagulase test. Streptococci were identified using a systematic approach of the Christie-Atkins-MunchPetersen (CAMP) test and esculin hydrolysis included in the MTKT plate, testing for Lancefield group by latex agglutination using a Prolex kit (Pro-Lab Diagnostics, Round Rock, TX), and leucine aminopeptidase (LAP) and pyrrolidonyl arylamidase (PYR) enzyme tests. All GN bacteria were identified by API $20 \mathrm{E}$ test strips (bioMérieux, Durham, NC). Other organisms, such as Bacillus and yeast, were identified by Gram stain and other general laboratory procedures. All bacteria isolated from a sample were reported and the following levels used to report the number of colonies: low (1-10 colonies), medium (11-49 colonies), and high ( $\geq 50$ colonies).
Minnesota Easy Culture System II Bi-Plates and TriPlates were labeled with the herd, cow, and quarter identification, and only 1 milk sample was plated on each plate. Sterile cotton-tipped swabs were saturated in the milk sample, and then used to swab the sample onto each half of the Bi-Plate. A new sterile cottontipped swab was saturated in the milk sample, and then used to swab the sample onto each third of the Tri-Plate. The Bi-Plates and Tri-Plates were incubated inverted at $37^{\circ} \mathrm{C}$ for 18 to $24 \mathrm{~h}$. After initial incubation, 2 inexperienced readers examined the plates and recorded the culture results using the Minnesota Easy Culture System II User's Manual (first edition; University of Minnesota Laboratory for Udder Health, $2004)$ to identify any growth present. The 2 readers examined the plates at different times of day, within $5 \mathrm{~h}$ of each other, and the plates were kept at room temperature between readers. If no growth was present, the plate was incubated for an additional $24 \mathrm{~h}$ and final results were recorded the following day. For each sample, the 2 readers were asked to classify the culture results into the following diagnostic categories (yes/no for each category): NG, mixed (growth of 2 organisms), contaminated (growth or 3 or more organisms), GP, GN, Staphylococcus spp., Streptococcus spp., Strep. agalactiae, Strep. dysgalactiae, Strep. uberis, Enterococcus spp., Staph. aureus, CNS, E. coli, Klebsiella spp., and other. If the culture was classified as contaminated, no attempt was made by the readers to further classify the bacterial growth present. However, if the culture was classified as mixed, the readers tried to identify the 2 species of bacteria present. The 2 readers were blinded to each other's results as well as those of the standard laboratory culture method. At the end of each week, final culture results from all 3 sources were entered into an Excel spreadsheet (Microsoft Corp., Redmond, WA): standard laboratory culture results, Bi-Plate and Tri-Plate results from reader 1 , and Bi-Plate and TriPlate results from reader 2 .

\section{Statistical Analysis}

Diagnostic test characteristics, including true prevalence, apparent prevalence, specificity (Sp), sensitivity (Se), accuracy (AC), and positive (PPV) and negative predictive values (NPV) were calculated as described by Dohoo et al. (2009) for the Bi-Plate and Tri-Plate at each category of culture interpretation, by comparing each reader's classifications to the results of the standard laboratory culture method. It should be noted that AC is referred to as "observed agreement" in Dohoo et al. (2009). For the current study, AC was calculated as the total number of organisms correctly 
classified (sum of true positives plus true negatives) divided by the total number of organisms considered (sum of true positives, true negatives, false positives, and false negatives).

Kappa statistics, measuring agreement beyond chance, were calculated for both the Bi-Plate and TriPlate at each category of interpretation to measure interreader agreement between the 2 inexperienced readers and to measure agreement between each reader and standard laboratory culture. Agreement was considered almost perfect $(>80 \%)$, substantial $(60-80 \%)$, moderate $(40-60 \%)$, fair $(20-40 \%)$, or slight $(<20 \%)$, as described by Dohoo et al. (2009).

\section{RESULTS AND DISCUSSION}

Although previous studies have found that the Minnesota Easy Culture System can be used to classify mastitis infections into broad categories, such as NG, GN, or GP, the objective of this study was to ascertain whether this OFC system could be used to make a more precise diagnose of the pathogen causing mastitis at either the genus or species level. A total of 283 field samples submitted to the University of Minnesota Laboratory for Udder Health were originally included in this study. However, 75 (27\%) of the Bi-Plate cultures and $78(28 \%)$ of the Tri-Plate cultures were categorized as contaminated (growth of 3 or more different organisms) by at least 1 of the 3 readers. If a reader categorized a culture as contaminated, no further attempt was made to categorize the bacterial growth present and, there- fore, these samples were excluded from the analysis for assessment of the other diagnostic categories.

The distribution of mastitis pathogens recovered by standard laboratory culture is described in Table 1. For samples comparing laboratory culture to the Bi-Plate of the noncontaminated samples showing bacterial growth, the most common organisms detected by laboratory culture were CNS (37.1\%), Strep. uberis (18.0\%), Staph. aureus (11.7\%), E. coli (7.8\%), Strep. dysgalactiae (7.3\%), Enterococcus spp. (6.8\%), and Klebsiella spp. (6.8\%). Streptococcus agalactiae was omitted from the final analysis due to insufficient numbers of isolates found. The "other" category included the following organisms identified by the laboratory: Trueperella pyogenes, Bacillus spp., Serratia spp., Pseudomonas spp., Prototheca spp., and yeast. Although in retrospect, a sufficient number of samples had growth of Aerococcus spp., it was not originally included as an optional diagnostic category for the untrained readers to record because we did not have an a priori expectation that it would be a prevalent organism. Therefore, we did not ask the readers to try to specifically identify this organism. Additionally, no guidance (i.e., no pictures) on the morphological identification of Aerococcus spp. was provided in the first edition of the Minnesota Easy Culture System User's Manual.

Some of the milk samples used in this study were frozen on farm before being shipped to the Laboratory for Udder Health. However, samples used for OFC on dairy farms will most likely be fresh, non-frozen samples. Freezing samples will have some effect on

Table 1. Gold standard microbiology results of samples from which 1 or 2 bacteria were isolated

\begin{tabular}{|c|c|c|c|c|}
\hline \multirow[b]{2}{*}{ Gold standard result } & \multicolumn{2}{|c|}{ Bi-Plate $^{1}$} & \multicolumn{2}{|c|}{ Tri-Plate $^{1}$} \\
\hline & $\mathrm{n}$ & $\%$ & $\mathrm{n}$ & $\%$ \\
\hline No bacterial growth & 31 & 15.1 & 31 & 14.9 \\
\hline Mixed & 53 & 25.9 & 47 & 22.6 \\
\hline Coagulase-negative staphylococci & 76 & 37.1 & 67 & 32.2 \\
\hline Streptococcus uberis & 37 & 18.0 & 37 & 17.8 \\
\hline Staphylococcus aureus & 24 & 11.7 & 23 & 11.1 \\
\hline Escherichia coli & 16 & 7.8 & 16 & 7.7 \\
\hline Streptococcus dysgalactiae & 15 & 7.3 & 13 & 6.3 \\
\hline Enterococcus spp. & 14 & 6.8 & 12 & 5.8 \\
\hline Klebsiella spp. & 14 & 6.8 & 15 & 7.2 \\
\hline Aerococcus spp. & 13 & 6.3 & 10 & 4.8 \\
\hline Trueperella pyogenes & 5 & 2.4 & 5 & 2.4 \\
\hline Bacillus spp. & 3 & 1.5 & 4 & 1.9 \\
\hline Serratia spp. & 3 & 1.5 & 3 & 1.4 \\
\hline Prototheca spp. & 2 & 1.0 & 2 & 1.0 \\
\hline Pseudomonas spp. & 2 & 1.0 & 2 & 1.0 \\
\hline Yeast & 1 & 0.5 & 2 & 1.0 \\
\hline Total samples ${ }^{2}$ & 205 & 100 & 208 & 100 \\
\hline
\end{tabular}

${ }^{1}$ Culture system from the Minnesota Easy Culture System II (University of Minnesota Laboratory for Udder Health, St. Paul).

${ }^{2}$ Pathogen numbers do not add up to the sample total because mixed samples were included. 
the ability to recover certain pathogens. In one study, freezing milk samples at $-20^{\circ} \mathrm{C}$ for $23 \mathrm{~d}$ resulted in an increased frequency of isolation of Strep. agalactiae and Staph. aureus compared with non-frozen samples (Villanueva et al., 1991). In another study, freezing samples decreased the number of $E$. coli isolates recovered, increased recovery of CNS, and had no effect on recovery of Streptococcus spp. or Staph. aureus (Schukken et al., 1989). Although freezing samples may have affected the prevalence of certain isolates recovered in our study, it should not have affected our comparison of results between the standard laboratory culture and Bi-Plate or Tri-Plate cultures (Se, Sp, AC, and interreader agreement). However, the prevalence of bacterial species isolated will affect the calculation of NPV and PPV. Low-prevalence pathogens (for example, Strep. uberis in this study) will have a high NPV, whereas high-prevalence pathogens will have a high PPV.

\section{Diagnostic Test Characteristics}

Bi-Plate Test Characteristics. The Bi-Plate test characteristics for each reader are presented in Tables 2 and 3. Diagnostic Sp, overall AC, and NPV were generally high $(>80 \%)$ for the Bi-Plate for the broad categories of NG, GP, GN, Staphylococcus spp., and Streptococcus spp. as well as for the more specific categories and other. Diagnostic Se and PPV were intermediate $(>60 \%)$ or high $(>80 \%)$ for the broad categories of NG, GP, GN, Staphylococcus spp. and Streptococcus spp., and for Staph. aureus, but were generally lower $(<60 \%)$ for the other more specific categories and other. When considering the test characteristics for the most basic levels of classification (NG, GP, and GN), the results of this study are consistent with those of a previous validation study conducted by Lago et al. (2006), wherein the Bi-Plate was evaluated for its ability to differentiate GP cases. In that study, Bi-Plate results were compared with standard laboratory culture results for 80 clinical mastitis samples and 87 fresh cow samples that showed a positive reaction using the California mastitis test. The results from that study were as follows: for clinical mastitis samples: $\mathrm{Se}=83 \%, \mathrm{Sp}=90 \%, \mathrm{PPV}=$ $83 \%$, and NPV $=90 \%$; and for California mastitis testpositive fresh-cow samples: $\mathrm{Se}=88 \%, \mathrm{Sp}=70 \%$, PPV $=80 \%$, and NPV $=81 \%$. In another study conducted by McCarron et al. (2009a) to evaluate the ability of the Bi-Plate to correctly diagnose GP growth in 262 cases of clinical mastitis, the reported Se (97.9\%) was higher and Sp (67.5\%) was lower than in the current study.

The diagnostic Sp, AC, and NPV of the Bi-Plate were high $(>80 \%)$ for the contaminated category. However, although the Sp was high $(>80 \%)$ for the mixed and combined mixed or contaminated categories, the $\mathrm{AC}$ and NPV were intermediate $(>60 \%)$. The Se and PPV were poor for these categories. In this study, the most likely result of misclassification of a contaminated culture result was that the reader classified the sample as GP. For example, using the Bi-Plate, of the 41 truly contaminated cultures that reader 1 misclassified, 30 of them were called GP. Of the 29 truly contaminated cultures that reader 2 misclassified, 25 were called GP.

Differences in Bi-Plate test characteristics between reader 1 and reader 2 were generally insignificant. One example of the difference between reader 1 and reader 2 is the ability to diagnose Staph. aureus. Reader 2 had a lower Se for Staph. aureus using the Bi-Plate (58 vs. $83 \%)$, although this difference was not significant $(95 \%$ CI overlap). Reader 2 also had a lower Se for the mixed and mixed or contaminated categories.

Tri-Plate Test Characteristics. The Tri-Plate test characteristics for each reader are presented in Tables 4 and 5. Diagnostic Sp, overall AC, and NPV values were generally high $(>80 \%)$ for the Tri-Plate for the broad categories of NG, GP, GN, Staphylococcus spp., and Streptococcus spp. as well as the other more specific categories and other. Diagnostic Se and PPV were intermediate $(>60 \%)$ or high $(>80 \%)$ for the broad categories of NG, GP, GN, Staphylococcus spp. and Streptococcus spp., and for Staph. aureus, but were generally lower $(<60 \%)$ for most other specific categories and other. In a previous Tri-Plate validation study, McCarron et al. (2009b) reported the test characteristics of the Tri-Plate when used by untrained readers to identify Staph. aureus and to differentiate streptococcal growth from other GP growth in 261 samples from clinical mastitis cases. For Staph. aureus, the Se (43.3 to $59.1 \%$ ) was slightly lower than in the current study. For differentiation of streptococcal growth, the Se was 77.8 to $88.9 \%$ and the Sp was 83.7 to $92.7 \%$. These results are not different from the current study.

The diagnostic Sp, AC, and NPV of the Tri-Plate were high $(>80 \%)$ for the contaminated category. The Sp was high (>80\%) for the mixed and combined mixed or contaminated categories; however, the AC and NPV were intermediate $(>60 \%)$ for these categories. The Se and PPV were poor for the contaminated, mixed, and mixed or contaminated categories. Differences in TriPlate test characteristics between reader 1 and reader 2 were generally insignificant and similar to the differences noted above for the Bi-Plate.

\section{Agreement}

Bi-Plate Agreement. When using the Bi-Plate, agreement between the 2 inexperienced readers and between each reader and the standard laboratory cul- 
Table 2. Test characteristics of the Bi-Plate (culture system from the Minnesota Easy Culture System II; University of Minnesota Laboratory for Udder Health, St. Paul) for samples from which 1 or 2 bacterial species were isolated $(\mathrm{n}=208)$

\begin{tabular}{|c|c|c|c|c|c|c|c|}
\hline \multirow[b]{2}{*}{ Interpretation } & \multicolumn{7}{|c|}{ Point estimate $(95 \%$ CI $)$} \\
\hline & True prevalence & $\begin{array}{c}\text { Apparent } \\
\text { prevalence }\end{array}$ & Sensitivity & Specificity & Accuracy & $\begin{array}{c}\text { Positive } \\
\text { predictive value }\end{array}$ & $\begin{array}{c}\text { Negative } \\
\text { predictive value }\end{array}$ \\
\hline \multicolumn{8}{|c|}{ No bacterial growth } \\
\hline Reader 1 & $0.15(0.10-0.20)$ & $0.18(0.13-0.23)$ & $0.71(0.55-0.87)$ & $0.92(0.87-0.96)$ & $0.89(0.84-0.93)$ & $0.60(0.44-0.75)$ & $0.95(0.91-0.98)$ \\
\hline Reader 2 & & $0.25(0.19-0.30)$ & $0.84(0.71-0.97)$ & $0.86(0.81-0.91)$ & $0.86(0.81-0.90)$ & $0.51(0.37-0.65)$ & $0.97(0.94-1.00)$ \\
\hline \multicolumn{8}{|l|}{ Mixed growth } \\
\hline Reader 1 & $0.26(0.20-0.31)$ & $0.10(0.06-0.14)$ & $0.17(0.07-0.27)$ & $0.92(0.88-0.97)$ & $0.73(0.67-0.79)$ & $0.43(0.22-0.64)$ & $0.77(0.70-0.83)$ \\
\hline Reader 2 & & $0.01(0-0.02)$ & 0 & $0.99(0.97-1.00)$ & $0.74(0.68-0.80)$ & 0 & $0.74(0.68-0.80)$ \\
\hline \multicolumn{8}{|l|}{ Gram-positive } \\
\hline Reader 1 & $0.75(0.69-0.81)$ & $0.69(0.63-0.76)$ & $0.85(0.80-0.91)$ & $0.79(0.68-0.90)$ & $0.84(0.79-0.89)$ & $0.92(0.88-0.97)$ & $0.64(0.52-0.76)$ \\
\hline Reader 2 & & $0.63(0.56-0.70)$ & $0.80(0.73-0.86)$ & $0.87(0.77-0.96)$ & $0.81(0.76-0.87)$ & $0.95(0.91-0.99)$ & $0.58(0.47-0.69)$ \\
\hline \multicolumn{8}{|l|}{ Gram-negative } \\
\hline Reader 1 & $0.17(0.12-0.22)$ & $0.19(0.13-0.24)$ & $0.72(0.58-0.87)$ & $0.92(0.89-0.96)$ & $0.89(0.85-0.93)$ & $0.67(0.52-0.82)$ & $0.94(0.91-0.98)$ \\
\hline Reader 2 & & $0.13(0.08-0.17)$ & $0.58(0.42-0.74)$ & $0.97(0.95-1.00)$ & $0.90(0.86-0.94)$ & $0.81(0.66-0.96)$ & $0.92(0.88-0.96)$ \\
\hline \multicolumn{8}{|c|}{ Streptococcus spp. } \\
\hline Reader 1 & $0.36(0.30-0.43)$ & $0.17(0.12-0.22)$ & $0.39(0.28-0.50)$ & $0.95(0.91-0.99)$ & $0.75(0.69-0.80)$ & $0.81(0.68-0.94)$ & $0.73(0.67-0.80)$ \\
\hline Reader 2 & & $0.26(0.20-0.32)$ & $0.59(0.48-0.70)$ & $0.92(0.87-0.96)$ & $0.80(0.74-0.85)$ & $0.80(0.69-0.91)$ & $0.80(0.73-0.86)$ \\
\hline \multicolumn{8}{|c|}{ Staphylococcus spp. } \\
\hline Reader 1 & $0.47(0.40-0.53)$ & $0.51(0.45-0.58)$ & $0.73(0.64-0.82)$ & $0.68(0.59-0.76)$ & $0.70(0.64-0.76)$ & $0.66(0.57-0.75)$ & $0.74(0.66-0.83)$ \\
\hline Reader 2 & & $0.37(0.31-0.44)$ & $0.60(0.50-0.70)$ & $0.83(0.76-0.90)$ & $0.72(0.66-0.78)$ & $0.75(0.66-0.85)$ & $0.70(0.62-0.78)$ \\
\hline \multicolumn{8}{|c|}{ Staphylococcus aureus } \\
\hline Reader 1 & $0.12(0.07-0.16)$ & $0.17(0.12-0.22)$ & $0.83(0.68-0.98)$ & $0.92(0.88-0.96)$ & $0.91(0.87-0.95)$ & $0.57(0.41-0.74)$ & $0.98(0.95-1.00)$ \\
\hline Reader 2 & & $0.11(0.06-0.15)$ & $0.58(0.39-0.78)$ & $0.96(0.93-0.99)$ & $0.91(0.88-0.95)$ & $0.64(0.44-0.84)$ & $0.95(0.92-0.98)$ \\
\hline \multicolumn{8}{|l|}{$\mathrm{CNS}$} \\
\hline Reader 1 & $0.37(0.30-0.43)$ & $0.37(0.31-0.44)$ & $0.55(0.44-0.66)$ & $0.74(0.66-0.81)$ & $0.69(0.60-0.73)$ & $0.55(0.43-0.66)$ & $0.74(0.67-0.82)$ \\
\hline Reader 2 & & $0.26(0.20-0.32)$ & $0.45(0.34-0.56)$ & $0.85(0.79-0.91)$ & $0.70(0.64-0.76)$ & $0.63(0.50-0.76)$ & $0.73(0.66-0.80)$ \\
\hline \multicolumn{8}{|c|}{ Streptococcus dysgalactiae } \\
\hline Reader 1 & $0.07(0.04-0.10)$ & $0.10(0.06-0.14)$ & $0.33(0.10-0.57)$ & $0.92(0.88-0.96)$ & $0.88(0.83-0.92)$ & $0.24(0.06-0.42)$ & $0.95(0.91-0.98)$ \\
\hline Reader 2 & & $0.22(0.16-0.27)$ & $0.47(0.21-0.72)$ & $0.80(0.75-0.86)$ & $0.78(0.72-0.84)$ & $0.16(0.05-0.26)$ & $0.95(0.92-0.98)$ \\
\hline \multicolumn{8}{|c|}{ Streptococcus uberis } \\
\hline Reader 1 & $0.18(0.13-0.23)$ & 0 & - & - & - & - & - \\
\hline Reader 2 & & $0.01(0-0.02)$ & $0.03(0-0.08)$ & $0.99(0.98-1.00)$ & $0.82(0.77-0.87)$ & $0.50(0-1.00)$ & $0.83(0.77-0.88)$ \\
\hline \multicolumn{8}{|c|}{ Enterococcus spp. } \\
\hline Reader 1 & $0.07(0.03-0.10)$ & 0 & - & - & - & - & - \\
\hline Reader 2 & & $0.03(0.01-0.05)$ & $0.07(0-0.21)$ & $0.97(0.95-1.00)$ & $0.91(0.88-0.95)$ & $0.17(0-0.47)$ & $0.94(0.90-0.97)$ \\
\hline \multicolumn{8}{|l|}{ Escherichia coli } \\
\hline Reader 1 & $0.08(0.04-0.11)$ & $0.12(0.07-0.16)$ & $0.69(0.46-0.92)$ & $0.93(0.90-0.97)$ & $0.91(0.88-0.95)$ & $0.45(0.26-0.67)$ & $0.97(0.94-1.00)$ \\
\hline Reader 2 & & $0.06(0.04-0.11)$ & $0.50(0.25-0.75)$ & $0.97(0.95-1.00)$ & $0.94(0.91-0.97)$ & $0.62(0.35-0.88)$ & $0.96(0.93-0.99)$ \\
\hline \multicolumn{8}{|l|}{ Klebsiella spp. } \\
\hline Reader 1 & $0.07(0.03-0.10)$ & $0.08(0.04-0.11)$ & $0.29(0.05-0.52)$ & $0.94(0.90-0.97)$ & $0.89(0.85-0.91)$ & $0.25(0.04-0.46)$ & $0.95(0.92-0.98)$ \\
\hline Reader 2 & & $0.06(0.03-0.10)$ & $0.36(0.11-0.61)$ & $0.96(0.93-0.99)$ & $0.92(0.88-0.96)$ & $0.39(0.12-0.65)$ & $0.95(0.92-0.98)$ \\
\hline \multicolumn{8}{|l|}{ Other } \\
\hline Reader 1 & $0.08(0.04-0.11)$ & $0.01(0-0.01)$ & 0 & $1.00(0.99-1.00)$ & $0.92(0.88-0.96)$ & 0 & $0.92(0.89-0.96)$ \\
\hline Reader 2 & & 0 & - & - & - & - & - \\
\hline
\end{tabular}




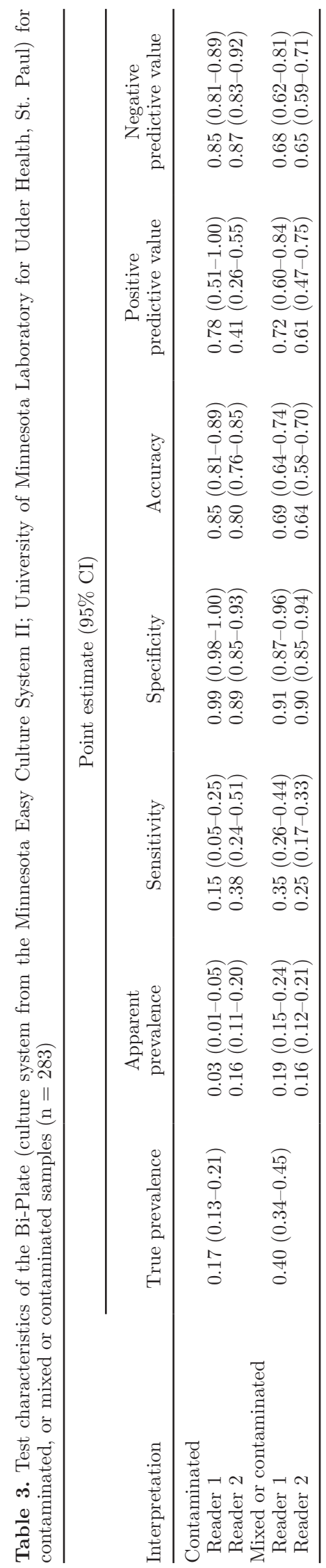

ture method was moderate $(40-60 \%)$ or substantial (60-80\%) for the more general categories of NG, GP, GN, Streptococcus spp., Staphylococcus spp., and for Staph. aureus and E. coli (Table 6). This is consistent with the study described previously, wherein McCarron et al. (2009a) reported a combined kappa value of 0.76 (substantial agreement) for 5 masked readers, 4 with limited microbiology training and 1 milk laboratory technician, on the classification of growth as GP. For all other more specific categories and the other, mixed, contaminated, and mixed or contaminated categories, agreement between readers, and between each reader and the laboratory was fair $(20-40 \%)$ or slight $(<20 \%)$.

Tri-Plate Agreement. When using the Tri-Plate, agreement between the 2 inexperienced readers and between each reader and the standard laboratory culture method was moderate $(40-60 \%)$ or substantial (60$80 \%$ ) for the more general categories of NG, GP, GN, Streptococcus spp., Staphylococcus spp., and for Staph. aureus and E. coli (Table 7). McCarron et al. (2009b) reported a kappa value of 0.51 (moderate agreement) for the identification of Staph. aureus growth, and a kappa value of 0.81 (almost perfect agreement) for differentiation of streptococcal growth. For most of the more specific categories and the mixed, contaminated, and mixed or contaminated categories, agreement between readers and between each reader and the laboratory was fair (20-40\%). For Strep. uberis and other, agreement between readers, and between each reader and the laboratory was slight $(<20 \%)$.

\section{Diagnostic Utility of the Minnesota Easy Culture System II}

In this study, Sp and overall AC were generally high for the Bi-Plate and Tri-Plate at each diagnostic category. However, we feel that having both a high Se and $\mathrm{Sp}$ is important to identify either general categories of infection or, more specifically, the actual species causing infection to guide strategic treatment or casemanagement decisions. In this study, Se of the Bi-Plate and Tri-Plate was generally high or intermediate for the broad categories of NG, GP, GN, Staphylococcus spp., and Streptococcus spp. Apart from Staph. aureus, however, both tests generally had poorer Se to identify other more specific categories of infection. Additionally, both the Bi-Plate and Tri-Plate had poor Se to identify samples as mixed or contaminated.

Several potential implications arise from these findings. From this and previous studies, it is clear that the Minnesota Easy Culture System II Bi-Plate or Tri-Plate can be used with confidence to categorize IMI into treatment groups based on the broad culture result categories of NG, GP, and GN. This study has 
Table 4. Test characteristics of the Tri-Plate (culture system from the Minnesota Easy Culture System II; University of Minnesota Laboratory for Udder Health, St. Paul) for samples from which 1 or 2 bacterial species were isolated $(n=205)$

\begin{tabular}{|c|c|c|c|c|c|c|c|}
\hline \multirow[b]{2}{*}{ Interpretation } & \multicolumn{7}{|c|}{ Point estimate (95\% CI) } \\
\hline & True prevalence & $\begin{array}{l}\text { Apparent } \\
\text { prevalence }\end{array}$ & Sensitivity & Specificity & Accuracy & $\begin{array}{c}\text { Positive } \\
\text { predictive value }\end{array}$ & $\begin{array}{c}\text { Negative } \\
\text { predictive value }\end{array}$ \\
\hline \multicolumn{8}{|c|}{ No bacterial growth } \\
\hline Reader 1 & \multirow[t]{2}{*}{$0.15(0.10-0.20)$} & $0.19(0.13-0.24)$ & $0.71(0.55-0.87)$ & $0.91(0.87-0.95)$ & $0.88(0.83-0.92)$ & $0.58(0.42-0.74)$ & $0.95(0.91-0.98)$ \\
\hline Reader 2 & & $0.27(0.21-0.33)$ & $0.90(0.80-1.00)$ & $0.85(0.79-0.90)$ & $0.85(0.81-0.90)$ & $0.51(0.38-0.64)$ & $0.98(0.96-1.00)$ \\
\hline \multicolumn{8}{|l|}{ Mixed } \\
\hline Reader 1 & \multirow[t]{2}{*}{$0.23(0.17-0.29)$} & $0.22(0.16-0.28)$ & $0.49(0.35-0.63)$ & $0.86(0.81-0.92)$ & $0.78(0.72-0.83)$ & $0.51(0.37-0.66)$ & $0.85(0.80-0.91)$ \\
\hline Reader 2 & & $0.02(0-0.04)$ & $0.04(0-0.10)$ & $0.99(0.97-1.00)$ & $0.77(0.71-0.83)$ & $0.50(0.01-0.99)$ & $0.78(0.72-0.83)$ \\
\hline \multicolumn{8}{|l|}{ Gram-positive } \\
\hline Reader 1 & \multirow{2}{*}{$0.74(0.68-0.80)$} & $0.70(0.64-0.76)$ & $0.86(0.81-0.92)$ & $0.76(0.65-0.87)$ & $0.83(0.78-0.89)$ & $0.91(0.86-0.96)$ & $0.66(0.54-0.78)$ \\
\hline Reader 2 & & $0.61(0.54-0.67)$ & $0.80(0.73-0.86)$ & $0.93(0.86-1.00)$ & $0.83(0.78-0.88)$ & $0.97(0.94-1.00)$ & $0.62(0.51-0.72)$ \\
\hline \multicolumn{8}{|l|}{ Gram-negative } \\
\hline Reader 1 & \multirow[t]{2}{*}{$0.18(0.13-0.23)$} & $0.18(0.12-0.23)$ & $0.78(0.65-0.92)$ & $0.96(0.93-0.99)$ & $0.93(0.89-0.96)$ & $0.81(0.68-0.94)$ & $0.95(0.92-0.99)$ \\
\hline Reader 2 & & $0.13(0.09-0.18)$ & $0.60(0.44-0.75)$ & $0.97(0.95-1.00)$ & $0.90(0.86-0.94)$ & $0.82(0.67-0.96)$ & $0.92(0.88-0.96)$ \\
\hline \multicolumn{8}{|c|}{ Streptococcus spp. } \\
\hline Reader 1 & \multirow{2}{*}{$0.33(0.27-0.40)$} & $0.32(0.26-0.39)$ & $0.81(0.72-0.90)$ & $0.92(0.87-0.97)$ & $0.88(0.84-0.93)$ & $0.83(0.74-0.92)$ & $0.91(0.86,0.96)$ \\
\hline Reader 2 & & $0.28(0.22-0.34)$ & $0.78(0.68-0.88)$ & $0.97(0.94-1.00)$ & $0.91(0.87-0.95)$ & $0.93(0.86-1.00)$ & $0.90(0.85,0.95)$ \\
\hline \multicolumn{8}{|c|}{ Staphylococcus spp. } \\
\hline Reader 1 & \multirow[t]{2}{*}{$0.42(0.36-0.49)$} & $0.48(0.41-0.55)$ & $0.72(0.63-0.82)$ & $0.70(0.62-0.79)$ & $0.71(0.65-0.77)$ & $0.64(0.55-0.74)$ & $0.78(0.70-0.86)$ \\
\hline Reader 2 & & $0.31(0.25-0.38)$ & $0.58(0.47-0.68)$ & $0.88(0.82-0.94)$ & $0.75(0.69-0.81)$ & $0.78(0.68-0.88)$ & $0.74(0.67-0.81)$ \\
\hline \multicolumn{8}{|c|}{ Staphylococcus aureus } \\
\hline Reader 1 & \multirow{2}{*}{$0.11(0.07-0.16)$} & $0.16(0.11-0.21)$ & $0.78(0.61-0.95)$ & $0.92(0.88-0.96)$ & $0.90(0.86-0.94)$ & $0.55(0.38-0.72)$ & $0.97(0.95-1.00)$ \\
\hline Reader 2 & & $0.07(0.04-0.11)$ & $0.52(0.32-0.73)$ & $0.98(0.97-1.00)$ & $0.93(0.90-0.97)$ & $0.80(0.60-1.00)$ & $0.94(0.91-0.98)$ \\
\hline \multicolumn{8}{|l|}{ CNS } \\
\hline Reader 1 & \multirow[t]{2}{*}{$0.33(0.26-0.39)$} & $0.33(0.27-0.40)$ & $0.49(0.37-0.61)$ & $0.75(0.67-0.82)$ & $0.66(0.60-0.73)$ & $0.49(0.37-0.60)$ & $0.75(0.70-0.82)$ \\
\hline Reader 2 & & $0.24(0.19-0.30)$ & $0.46(0.34-0.58)$ & $0.86(0.81-0.92)$ & $0.73(0.67-0.79)$ & $0.62(0.49-0.76)$ & $0.77(0.70-0.83)$ \\
\hline \multicolumn{8}{|c|}{ Streptococcus dysgalactiae } \\
\hline Reader 1 & \multirow{2}{*}{$0.06(0.03-0.10)$} & $0.17(0.12-0.22)$ & $0.85(0.65-1.00)$ & $0.88(0.83-0.93)$ & $0.88(0.83-0.92)$ & $0.32(0.17-0.48)$ & $0.99(0.97-1.00)$ \\
\hline Reader 2 & & $0.20(0.14-0.25)$ & $0.77(0.54-1.00)$ & $0.84(0.79-0.90)$ & $0.84(0.79-0.89)$ & $0.25(0.12-0.38)$ & $0.98(0.96-1.00)$ \\
\hline \multicolumn{8}{|c|}{ Streptococcus uberis } \\
\hline Reader 1 & \multirow[t]{2}{*}{$0.18(0.13-0.23)$} & $0.03(0.01-0.06)$ & $0.05(0-0.13)$ & $0.97(0.95-1.00)$ & $0.81(0.75-0.90)$ & $0.29(0-0.62)$ & $0.82(0.77-0.88)$ \\
\hline Reader 2 & & $0.03(0.01-0.06)$ & $0.11(0.01-0.12)$ & $0.98(0.96-1.00)$ & $0.82(0.77-0.88)$ & $0.57(0.21-0.94)$ & $0.83(0.78-0.89)$ \\
\hline \multicolumn{8}{|c|}{ Enterococcus spp. } \\
\hline Reader 1 & $0.06(0.03-0.09)$ & $0.04(0.02-0.07)$ & $0.25(0.01-0.50)$ & $0.97(0.94-0.99)$ & $0.93(0.89-0.96)$ & $0.33(0.03-0.64)$ & $0.95(0.93-0.98)$ \\
\hline Reader 2 & & $0.03(0.01-0.06)$ & $0.33(0.07-0.60)$ & $0.98(0.97-1.00)$ & $0.95(0.92-0.98)$ & $0.57(0.21-0.94)$ & $0.96(0.93-0.99)$ \\
\hline Escherichia col & & & & & & & \\
\hline Reader 1 & $0.08(0.04-0.12)$ & $0.10(0.06-0.14)$ & $0.63(0.39-0.86)$ & $0.94(0.91-0.98)$ & $0.92(0.88-0.96)$ & $0.48(0.26-0.69)$ & $0.97(0.94-0.99)$ \\
\hline Reader 2 & & $0.04(0.02-0.07)$ & $0.44(0.19-0.68)$ & $0.99(0.98-1.00)$ & $0.95(0.92-0.98)$ & $0.78(0.51-1.00)$ & $0.95(0.93-0.98)$ \\
\hline Klebsiella spp. & & & & & & & \\
\hline Reader 1 & $0.07(0.04-0.11)$ & $0.07(0.04-0.11)$ & $0.53(0.28-0.79)$ & $0.96(0.94-0.99)$ & $0.93(0.90-0.97)$ & $0.53(0.28-0.79)$ & $0.96(0.94-0.99)$ \\
\hline Reader 2 & & $0.06(0.03-0.10)$ & $0.33(0.10-0.57)$ & $0.96(0.93,0.99)$ & $0.91(0.87-0.95)$ & $0.39(0.12-0.65)$ & $0.95(0.92-0.98)$ \\
\hline Other & & & & & & & \\
\hline Reader 1 & $0.09(0.05-0.13)$ & $0.01(0-0.01)$ & 0 & $1.00(0.98-1.00)$ & $0.90(0.86-0.94)$ & 0 & $0.91(0.87-0.95)$ \\
\hline Reader 2 & & $0.01(0-0.02)$ & 0 & $0.99(0.97-1.00)$ & $0.90(0.86-0.94)$ & 0 & $0.91(0.87-0.95)$ \\
\hline
\end{tabular}




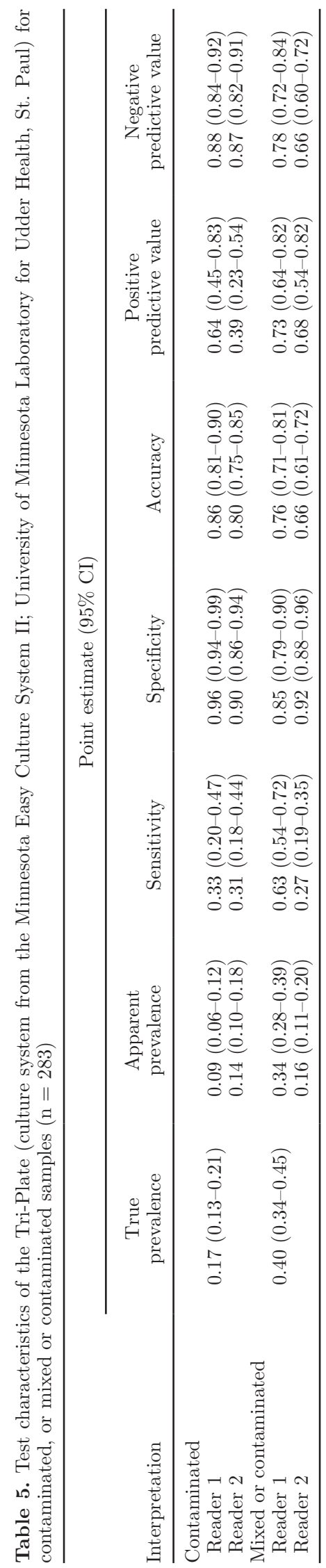

also established that users may further categorize GP infections as caused by Staphylococcus spp. or Streptococcus spp. with reasonable confidence, particularly if using the Tri-Plate. Compared with the Bi-Plate, the Tri-Plate had a significantly higher Se, AC, and NPV for the interpretation category of Streptococcus spp. The Se of the Tri-Plate was also significantly higher for Strep. dysgalactiae and Enterococcus spp. These differences may be explained by the additional medium (MTKT) present on the Tri-Plate, which selects for catalase-negative, GP cocci and would help users distinguish between GP growth caused by Streptococcus spp. and Staphylococcus spp. This may lead users to choose the Tri-Plate over the Bi-Plate, particularly in cases where this information would be used to make a different treatment or management decision regarding a case of clinical mastitis. However, the Tri-Plate is more expensive than the Bi-Plate, so users should weigh whether this additional certainty in diagnosing Streptococcus spp. would justify the additional cost.

Being able to distinguish between Staphylococcus spp. and Streptococcus spp. may aid in the identification of Staph. aureus (to differentiate Staph. aureus from hemolytic streptococci). Several factors should be considered when attempting to diagnose Staph. aureus using an OFC system. The primary approach by which users are able to identify growth caused by Staph. aureus is the presence of hemolysis of blood cells in the culture medium that appears as a clear zone around the bacterial colonies. Users should be aware that not all strains of Staph. aureus will exhibit this characteristic hemolysis, and some streptococci and non-aureus species of staphylococci will also exhibit hemolysis. Although both the Bi-Plate and Tri-Plate had a high Sp and intermediate Se to detect Staph. aureus, the consequences of a false-positive or false-negative result should be considered. Potential consequences of a falsepositive result include treating, segregating, or culling a cow that does not have Staph. aureus, and consequences of a false-negative result could include retaining a cow with Staph. aureus in the normal milking string, which increases the risk of transmission to other cows. Users might consider using ancillary testing on farm (such as the tube coagulase test) or confirmatory testing by a commercial diagnostic laboratory to confirm the identification of Staph. aureus when the consequences of a false positive are unacceptable.

The results of this study suggest that using the BiPlate or Tri-Plate to identify specific bacterial species, other than Staph. aureus, will frequently lead to inaccurate results and should not be attempted. This is one limitation of the Minnesota Easy Culture System II. For example, users may not be able to reliably differentiate GN growth as E. coli or Klebsiella, or strep- 
Table 6. Interreader agreement using the Bi-Plate (culture system from the Minnesota Easy Culture System II; University of Minnesota Laboratory for Udder Health, St. Paul)

\begin{tabular}{lccc}
\hline & \multicolumn{3}{c}{ Kappa $(95 \%$ CI $)$} \\
\cline { 2 - 4 } & $\begin{array}{c}\text { Reader 1 vs. } \\
\text { laboratory }\end{array}$ & $\begin{array}{c}\text { Reader } 2 \text { vs. } \\
\text { laboratory }\end{array}$ & Reader 1 vs. 2 \\
\hline Interpretation & $0.58(0.51-0.65)$ & $0.55(0.48-0.62)$ & $0.73(0.66-0.79)$ \\
No bacterial growth & $0.20(0.16-0.25)$ & $0.27(0.22-0.33)$ & $0.26(0.21-0.31)$ \\
Contaminated & $0.12(0.07-0.16)$ & 0 & 0 \\
Mixed & $0.29(0.23-0.34)$ & $0.16(0.12-0.20)$ & $0.44(0.38-0.50)$ \\
Mixed or contaminated & $0.60(0.53-0.66)$ & $0.57(0.50-0.64)$ & $0.82(0.77-0.87)$ \\
Gram-positive & $0.63(0.56-0.69)$ & $0.62(0.56-0.69)$ & $0.77(0.71-0.82)$ \\
Gram-negative & $0.38(0.31-0.44)$ & $0.54(0.47-0.60)$ & $0.46(0.39-0.53)$ \\
Streptococcus spp. & $0.41(0.34-0.47)$ & $0.43(0.37-0.50)$ & $0.47(0.40-0.53)$ \\
Staphylococcus spp. & $0.63(0.56-0.69)$ & $0.56(0.49-0.63)$ & $0.62(0.55-0.68)$ \\
Staphylococcus aureus & $0.29(0.23-0.35)$ & $0.32(0.25-0.38)$ & $0.42(0.36-0.49)$ \\
CNS & $0.21(0.16-0.27)$ & $0.14(0.09-0.19)$ & $0.33(0.27-0.40)$ \\
Streptococcus dysgalactiae & 0 & $0.03(0.01-0.06)$ & 0 \\
Streptococcus uberis & 0 & $0.06(0.03-0.10)$ & 0 \\
Enterococcus spp. & $0.50(0.44-0.57)$ & $0.52(0.45-0.59)$ & $0.44(0.37-0.51)$ \\
Escherichia coli & $0.21(0.16-0.27)$ & $0.33(0.26-0.39)$ & $0.30(0.23-0.36)$ \\
Klebsiella spp. & 0 & 0 & 0 \\
Other & & & \\
\hline
\end{tabular}

tococcal growth as Strep. uberis or Strep. dysgalactiae. Whereas mild or moderate mastitis infections caused by $E$. coli typically have high cure rates, the same is not true for Klebsiella. Streptococcus uberis infections are also more likely to become chronic infections, with lower cure rates compared with other environmental streptococci. Users of OFC systems should be aware of this limitation, and consider using a commercial diagnostic laboratory to help diagnose cases of mastitis that do not respond to therapy. Misclassification of some species of bacteria (e.g., E. coli vs. Klebsiella) may or may not be important, depending on whether the onfarm mastitis treatment protocols distinguish between such organisms.
In this study, a high percentage of samples were classified as contaminated. However, this level of apparent contamination may be due to the fact that many of the samples were composite samples (milk taken from all 4 quarters). Composite samples are more likely to appear contaminated either because different bacteria are present in the milk from each quarter, or because it is more difficult to collect a clean, noncontaminated sample from all 4 quarters. The results of this study suggest that on-farm users may have difficulty correctly identifying a culture result as contaminated. This underlines the importance of being able to collect an aseptic sample from an individual quarter for use in OFC systems. If a contaminated culture result

Table 7. Interreader agreement using the Tri-Plate (culture system from the Minnesota Easy Culture System II; University of Minnesota Laboratory for Udder Health, St. Paul)

\begin{tabular}{|c|c|c|c|}
\hline \multirow[b]{2}{*}{ Interpretation } & \multicolumn{3}{|c|}{ Kappa $(95 \%$ CI $)$} \\
\hline & $\begin{array}{c}\text { Reader } 1 \text { vs. } \\
\text { laboratory }\end{array}$ & $\begin{array}{c}\text { Reader } 2 \text { vs. } \\
\text { laboratory }\end{array}$ & Reader 1 vs. 2 \\
\hline No bacterial growth & $0.57(0.50-0.63)$ & $0.57(0.50-0.64)$ & $0.77(0.71-0.83)$ \\
\hline Contaminated & $0.37(0.31-0.42)$ & $0.23(0.18-0.28)$ & $0.34(0.28-0.39)$ \\
\hline Mixed & $0.36(0.29-0.42)$ & $0.04(0.02-0.07)$ & $0.09(0.05-0.13)$ \\
\hline Mixed or contaminated & $0.49(0.43-0.54)$ & $0.21(0.16-0.26)$ & $0.31(0.26-0.36)$ \\
\hline Gram-positive & $0.59(0.53-0.66)$ & $0.62(0.55-0.69)$ & $0.78(0.72-0.84)$ \\
\hline Gram-negative & $0.75(0.69-0.81)$ & $0.63(0.57-0.70)$ & $0.79(0.74-0.85)$ \\
\hline Streptococcus spp. & $0.73(0.67-0.79)$ & $0.78(0.73-0.84)$ & $0.85(0.80-0.90)$ \\
\hline Staphylococcus spp. & $0.42(0.35-0.49)$ & $0.47(0.40-0.54)$ & $0.56(0.50-0.63)$ \\
\hline Staphylococcus aureus & $0.59(0.52-0.66)$ & $0.60(0.53-0.66)$ & $0.49(0.42-0.56)$ \\
\hline CNS & $0.24(0.18-0.30)$ & $0.35(0.28-0.41)$ & $0.34(0.28-0.41)$ \\
\hline Streptococcus dysgalactiae & $0.41(0.35-0.48)$ & $0.31(0.25-0.38)$ & $0.64(0.57-0.70)$ \\
\hline Streptococcus uberis & $0.04(0.01-0.06)$ & $0.13(0.09-0.18)$ & $0.11(0.07-0.16)$ \\
\hline Enterococcus spp. & $0.25(0.19-0.31)$ & $0.40(0.33-0.46)$ & $0.35(0.29-0.42)$ \\
\hline Escherichia coli & $0.50(0.43-0.56)$ & $0.53(0.47-0.60)$ & $0.36(0.30-0.43)$ \\
\hline Klebsiella spp. & $0.50(0.43-0.57)$ & $0.31(0.25-0.37)$ & $0.46(0.40-0.53)$ \\
\hline Other & 0 & 0 & 0 \\
\hline
\end{tabular}


is misclassified on farm, one potential consequence is that the producer chooses an inappropriate treatment protocol for the affected cow. Another consequence of misclassification of contaminated cultures may be failure to recognize that a procedural problem exists that resulted in the contamination of the sample or culture plate. Monitoring the percentage of quarter samples that are contaminated will be an important component of quality control for an OFC program.

Based on the results of this study, a second edition of the Minnesota Easy Culture System II User's Guide has been published (University of Minnesota Laboratory for Udder Health, 2013), which encourages users to limit culture interpretation to the broad categories of NG, GP, GN, Staphylococcus spp., Streptococcus spp., and species-specific identification of Staph. aureus. The second edition of the User's Guide also provides guidance on identification of contaminated quarter milk samples and stresses the importance of on-farm laboratory quality control and periodic verification of $\mathrm{OFC}$ results with a reference laboratory.

\section{CONCLUSIONS}

The Minnesota Easy Culture System II Bi-Plate and Tri-Plate are useful tools for dairy producers to rapidly obtain diagnostic results for clinical mastitis cases, and this information can then be used to guide strategic or selective treatment decisions. Assuming that it is a priority to have both a high diagnostic Se and Sp to identify categories of infection or actual species causing infection to guide strategic treatment decisions, our conclusion was that Bi-Plate and TriPlate results will be most reliable when used to classify infections in broad diagnostic categories such as NG, GP, or GN growth. The Bi-Plate and Tri-Plate will have intermediate ability to identify infections as being caused by Staphylococcus spp., Streptococcus spp., or Staph. aureus. Although overall numerical differences in test characteristics were small, the Tri-Plate was more accurate than the Bi-Plate for classifying infections as Streptococcus spp. With the possible exception of Staph. aureus, on-farm users should refrain from using the Minnesota Easy Culture System II to diagnose the cause of mastitis infections at the species level.

\section{REFERENCES}

Bartlett, P. C., G. Y. Miller, S. E. Lance, and L. E. Heider. 1992. Clinical mastitis and intramammary infections on Ohio dairy farms. Prev. Vet. Med. 12:59-71.

Dohoo, I., W. Martin, and H. Stryhn. 2009. Screening and diagnostic tests. Pages 91-134 in Veterinary Epidemiologic Research. 2nd ed. AVC Inc., Charlottetown, Prince Edward Island, Canada.

Guterbock, W. M., A. L. Van Eenennaam, R. J. Anderson, I. A. Gardner, J. S. Cullor, and C. A. Holmberg. 1993. Efficacy of intramam- mary antibiotic therapy for treatment of clinical mastitis caused by environmental pathogens. J. Dairy Sci. 76:3437-3444.

Jones, M., J. Hochhalter, A. Lago, R. Bey, and S. Godden. 2006. Validation of the Minnesota Easy Culture System II: Results from inlab Tri-Plate culture versus standard laboratory culture, and TriPlate inter-reader agreement. Pages 299-300 in Proc. 39th Annu. Conv. Am. Assoc. Bovine Pract. American Association of Bovine Practitioners, Stillwater, OK.

Lago, A., S. Godden, R. Bey, K. Leslie, R. Dingwell, and P. Ruegg. 2006. Validation of the Minnesota Easy Culture System II: Results from on-farm Bi-Plate culture versus standard laboratory culture. Pages 250-251 in Proc. 39th Annu. Conv. Am. Assoc. Bovine Pract. American Association of Bovine Practitioners, Stillwater, OK.

Lago, A., S. M. Godden, R. Bey, P. L. Ruegg, and K. Leslie. 2011a. The selective treatment of clinical mastitis based on on-farm cul ture results: I. Effects on antibiotic use, milk withholding time, and short-term clinical and bacteriological outcomes. J. Dairy Sci. 94:4441-4456

Lago, A., S. M. Godden, R. Bey, P. L. Ruegg, and K. Leslie. 2011b. The selective treatment of clinical mastitis based on on-farm culture results: II. Effects on lactation performance, including clinical mastitis recurrence, somatic cell count, milk production, and cow survival. J. Dairy Sci. 94:4457-4467.

MacDonald, K., G. Keefe, I. Dohoo, K. Leslie, and J. P. Roy. 2011. Promoting judicious antibiotic use: On-farm culture-based treatment strategies. Pages 269-275 in Udder Health and Communication. H. Hogeveen and T. J. G. M. Lam. Wageningen Academic Publishers, Wageningen, the Netherlands.

McCarron, J. L., G. P. Keefe, S. L. McKenna, I. R. Dohoo, and D. E. Poole. 2009a. Laboratory evaluation of 3M Petrifilms and University of Minnesota Bi-plates as potential on-farm tests for clinical mastitis. J. Dairy Sci. 92:2297-2305

McCarron, J. L., G. P. Keefe, S. L. McKenna, I. R. Dohoo, and D. E. Poole. 2009b. Evaluation of the University of Minnesota Triplate and 3M Petrifilm for the isolation of Staphylococcus aureus and Streptococcus species from clinically mastitic milk samples. J. Dairy Sci. 92:5326-5333.

Morin, D. E., R. D. Shanks, and G. C. McCoy. 1998. Comparison of antibiotic administration in conjunction with supportive measures versus supportive measures alone for treatment of dairy cows with clinical mastitis. J. Am. Vet. Med. Assoc. 213:676-684.

NMC (National Mastitis Council). 1999. Laboratory Handbook on Bovine Mastitis. NMC, Madison, WI.

Olde Riekerink, R., H. Barkema, D. Poole, D. Kelton, and D. Scholl. 2008. Risk factors for incidence rate of clinical mastitis in a nationwide study on Canadian dairy farms. Page 204 in Proc. 46th Annu. Mtg. Nat. Mast. Counc., San Antonio, TX. National Mastitis Council, Madison, WI.

Oliver, S. P., R. A. Almeida, B. E. Gillespie, S. J. Headrick, H. H. Dowlen, D. L. Johnson, K. C. Lamar, S. T. Chester, and W. M. Moseley. 2004. Extended ceftiofur therapy for treatment of experimentally-induced Streptococcus uberis mastitis in lactating dairy cattle. J. Dairy Sci. 87:3322-3329.

Pinzón-Sánchez, C., V. E. Cabrera, and P. L. Ruegg. 2011. Decision tree analysis of treatment strategies for mild and moderate cases of clinical mastitis occurring in early lactation. J. Dairy Sci. 94:1873-1892.

Pol, M., and P. L. Ruegg. 2007. Relationship between antimicrobial drug usage and antimicrobial susceptibility of gram-positive mastitis pathogens. J. Dairy Sci. 90:262-273.

Roberson, J. R. 2003. Establishing treatment protocols for clinical mastitis. Vet. Clin. North Am. Food Anim. Pract. 19:223-234.

Schukken, Y. H., J. A. H. Smit, F. J. Grommers, D. Vandegeer, and A. Brand. 1989. Effect of freezing on bacteriologic culturing of mastitis milk samples. J. Dairy Sci. 72:1900-1906.

Schukken, Y. H., M. J. Zurakowski, B. J. Rauch, B. Gross, L. L. Tikofsky, and F. L. Welcome. 2013. Noninferiority trial comparing a first-generation cephalosporin with a third-generation cephalosporin in the treatment of nonsevere clinical mastitis in dairy cows. J. Dairy Sci. 96:6763-6774. 
University of Minnesota Laboratory for Udder Health. 2004. Minnesota Easy Culture System II User's Manual. University of Minnesota, Saint Paul.

University of Minnesota Laboratory for Udder Health. 2013. Minnesota Easy Culture System II User's Manual. 2nd ed. University of Minnesota, Saint Paul.

Villanueva, M. R., J. W. Tyler, and R. C. Thurmond. 1991. Recovery of Streptococcus agalactiae and Staphylococcus aureus from fresh and frozen bovine milk. J. Am. Vet. Med. Assoc. 198:1398-1400.
Wilson, D. J., R. N. Gonzalez, K. L. Case, L. L. Garrison, and Y. T. Grohn. 1999. Comparison of seven antibiotic treatments with no treatment for bacteriological efficacy against bovine mastitis pathogens. J. Dairy Sci. 82:1664-1670. 